\title{
Revista de Letras
}

ISSN: 2179-5282

\section{EDITORIAL}

Como editores da Revista de Letras da UTFPR-Curitiba, do Departamento Acadêmico de Linguagem e Comunicação - DALIC, expressamos, mais uma vez, o sentimento de dever cumprido com a publicação do 19 .o volume, n. 25 , de jan./jun. de 2017.

A Revista de Letras da UTFPR-Curitiba, nessa edição de tema livre, está composta de nove artigos de vários autores de diversas universidades renomadas do Brasil. Há quatro artigos de Estudos Linguísticos: da Universidade Federal do Rio Grande do Sul, Universidade Federal do Paraná, Universidade Federal de Tocantins e Instituto Federal Fluminense; três artigos de Estudos Literários: da Universidade Federal de Rondônia, Universidade Federal do Paraná e Sesi de São Paulo; e dois artigos de Ensino: da Universidade Federal do Recôncavo da Bahia e Universidade Estadual de Campinas com a Universidade de Brasília.

Aproveitamos também para agradecer os pareceristas ad hoc, da UTFPR e oriundos de diversas outras instituições do país, com sua colaboração irrestrita, avaliando os artigos. Estendo os agradecimentos aos colaboradores que nos auxiliaram na correção da normatização, das questões gramaticais dos artigos e dos abstracts, com a postagem no site; especialmente aos alunos Jope Leão Lobo (UTFPR-Curitiba/PPGEL) e Camila Queiroz; enfim, a todos que colaboraram com que mais essa edição fosse publicada, principalmente, aos autores que atenderam a nossa chamada para submissão, enviando os seus artigos.

Desejamos que a leitura dos artigos contribua para reflexões acerca de várias temáticas na área de Letras, ampliando os horizontes e suscitando novas pesquisas!

Profa. Dra. Alice Atsuko Matsuda

Editora-Chefe

Curitiba, jan./jun. de 2017. 